\title{
Impact of Internet Addiction on Academic Performance of Post-Graduate Students
}

\author{
Uttara Kumbhar
}

Research Scholar, Regional Institute of Education, Bhubaneswar, Odisha, India

Corresponding author: uttarakumbhar7@gmail.com

Received: 19-05-2021 Revised: 27-07-2021 Accepted: 05-08-2021

\begin{abstract}
The Covid-19 situation has significantly disrupted normal activities globally. During this pandemic, people around the world are facing many mental health problems. Particularly excessive use of internet may become a serious problem among teens. The aim of this study was to study the impact of internet addiction on academic achievement of postgraduate final year students studying in govt college, Sundargarh during Covid-19. The study also focuses on the gender difference, correlation between internet addiction and academic achievement and level of internet addiction of Postgraduate final year students. For collection of data, a sample of 48 final year postgraduate students consisting of 24 male and 24 female were selected purposively. Standardized Internet Addiction Test (IAT) developed by Young was administered for their responses and CGPA scores for the previous semester were collected and analysed using both inferential and descriptive statistics like mean, SD, correlation, percentage and t-test. The results of this study indicated that internet addiction has negative impact on academic achievement of postgraduate final year students. Results also shows that there is no significant difference in internet addiction of postgraduate final year students in relation to their gender and correlation between internet addiction and academic achievement of postgraduate final year students is weakest negative correlation.
\end{abstract}

Keywords: Internet Addiction, Academic Achievement, PG students, Covid-19

The human beings are the supreme and finest creation of God who graced with numerous qualities. It is education that makes possible to explore those rare qualities at the right moment. Education is for the human beings. It is education that converts an individual to a cultural and social being. Without education an individual is not different to that of an animal. The whole world has suffering from Corona virus disease since last 1 year. Our Indian government announced lockdown to seeing the horrors of Covid-19. Schools, colleges and other educational institution are closed since the time of lockdown. Due to the closure of all educational institutions, the students have to stay at home. Lockdown has made a great impact on the studies of the students. The government has announced online classes, keeping in mind that there was a huge impact on the education of the students in lockdown. Children are using mobile phone and internet more and more for their online classes as well as other activities. Internet is accepted as a widely channel for information exchange and networking. Large number of people in the world benefited by using internet. The benefits of the using internet have been widely investigated and include keeping in touch with friends, making vacations plan, managing finance, making relationship, assisting educational needs, teaching, learning etc.

\section{Internet addiction}

The internet has created life loads easier by creating

How to cite this article: Kumbhar, U. (2021). Impact of Internet Addiction on Academic Performance of Post-Graduate Students. Educational Quest: An Int. J. Edu. Appl. Soc. Sci., 12(2): 153-159.

Source of Support: None; Conflict of Interest: None की 
info a lot of accessible to all or any and making connections with different people around the world. However, it has also led a lot of people to spend too much time in front of the mobile phone, computer and laptop, so much so that it becomes the centre of their lives. Internet addiction is characterized by excessive or poorly controlled preoccupations, urges or behaviour s relating to computer use and net access that led to impairment and distress.

\section{Academic achievement}

Educational achievement is one of the important elements of the whole educational system. It is considered as a major benchmark of education. Educational Achievement is the product of the teaching cum learning context provided to the students in educational institutions, which will determine by the grades or marks obtained in the specific examination. In general, it shows the learning outcome of learners' which is essential for a series of planned activity. Academic accomplishment plays a big impact on motivation. Rather, academic achievement shows a stimulating impact on success.

\section{Literature review}

Analysis of research findings have shown that internet addiction adversely affects one's physical health, family life, and academic performance. Excessive use of internet is a cause of academic problems like decline in study habits, significant drop in grades, missing classes, poor integration in co-curricular activities etc. Now a days children, adolescent, adult all ages of peoples are internet addicted. Besides, student's internet addicts usually suffer from severe psychological problems, like anxiety, depression, feeling concern that life without internet would be boring, empty, and joyless and they also feeling loneliness and social isolation. In covid -19 situation all level of students is using internet.

The university students are considered as highrisk group for internet addiction suggested by Young and Rogers (1998). Suhail and Bargees (2006) reported that some benefits of internet usages of college students. They instructed that internet usages impact on education in a positive approach. It helps to increasing communication with friends and teachers, improving study habits and study hours and also increasing access to educational databases and libraries. Orhan and Nadir (2017) studied on exploring the impact of internet addiction on academic achievement. They found that the relationship of internet addiction and academic achievement is a negative correlation. Various studies have established that internet addiction has a negative impact on academic success of the students. Shaigan and Khushgeet (2014) targeted on exploration of internet addiction among university students and their academic performance and they found negative impact of internet addiction on adolescents. Yunyun and Ping (2018) examined the relationship between internet addiction and academic achievement, the mediation role of academic engagement, and the cross-level moderating effect of classroom achievement norm. This study additionally revealed that the negative effect of internet addiction on adolescents' later academic achievement was mediated by disaffection and academic engagement at the individual level. Jave and Vural (2013) examined about the predictive effects of academic achievement, internet use duration, loneliness and shyness on internet addiction and found out negative results. Hamza, Abdalla, Mustafa, Muhmmed, and Husain (2021) investigated on effects of internet addiction on academic performance of medical students at Omdurman Islamic University: An online crosssectional study and they found that no significance association between internet addiction test scores and CGPA score. Various studies have reported the frequency of internet addiction among medical students and relationship between internet addiction and academic achievement of undergraduate medical students (Khan, Alvin, Shabbir and Rajput 2013; Arslaan, Raheem, Shazia and Sanniya 2020). On the basis of these existing literature, it was hypothesized that internet addiction would have negative impact on academic achievement of the post graduate students.

Some other studies reported on the gender differences in internet usage. Akhter (2013) found significant gender difference among students on internet addiction. He reported that Male students had higher internet addiction than female ones. Azizollah, and Enam (2016) reported that there was a significant relationship between internet addiction and academic achievement with gender of students and found no correlation between performance in 
history or math and internet use. Similar findings were reported by Orhan and Nadir (2017) that there is no gender impact of internet addiction. Keeping these results, it was hypothesized that there exists no significant difference in internet addiction of the postgraduate final year students in relation to their gender. Lin (2020) conducted a research on prevalence of internet addiction during the Covid-19 outbreak and its risk factors among junior high school students in Taiwan and found high prevalence rate of internet addiction among junior school students during the covid-19 outbreak.

\section{Rational of the study}

Presently a-days, it is regularly seen that with the headway of internet addiction cell phones, there is increment in number of mobile phones clients, particularly youthful forty-four grown-ups. As the after effect of mobile phones highlights and innovative upgrades are massively changes and, in this way, understudies never again need to visit a cybercafé to get internet offices. Research discoveries have demonstrated that over the top utilization of internet or internet addiction antagonistically influences one's physical welfare, increment in anxiety and stress, family life, and tutorial execution. Analysis of earlier studies shows that the internet addiction has negative impact on academic performance of the students. The imprisonment because of unfolds of covid-19 pandemic forced the students to be stayed their home and having to adopt mobile and internet for their online classes. The present study is designed to investigate the impact of internet addiction on academic achievement of Post Graduate students throughout this Covid-19 scenario.

\section{Objectives of the study}

Objectives of the present study related to the impact of internet addiction of postgraduate final year students and their academic success.

1. To study the level of internet addiction of postgraduate final year students.

2. To study the impact of internet addiction on academic success of the postgraduate final students.

3. To study the significant difference in internet addiction of the postgraduate final year students in relation to their gender.
4. To examine the correlation between internet addiction and academic achievement of the postgraduate final year students.

\section{Hypotheses of the study}

1. There exists negative impact of internet addiction on academic success of postgraduate final year students.

2. There exists no significant difference in internet addiction of the PG students in relation to their gender.

3. There exists no relationship between internet addiction and academic achievement of PG students.

\section{Delimitation of the study}

1. This study has been delimited to only 48 Postgraduate final year students.

2. The study was delimited to the 24 boys and 24 girls' postgraduate final year students.

3. The study was also delimited to only Govt. College, Sundargarh.

\section{Method and procedure}

For the present study the investigator has adopted the descriptive survey method which can tell us about what exists at present by determining the nature and degree of existing conditions because of the directness. This study implemented quantitative research designs.

\section{Sample}

In research it is the subject, object, individuals, institutions or geographical area about which the investigator is interested to study is called population. For the present study the population constituted all postgraduate final year students studying in govt. college, Sundargarh. For the present study the investigator used purposive sampling technique to drawing the sample. The investigator selected 24 boys and 24 girls' postgraduate final year students as the sample of the study.

\section{Instruments}

Here researcher used a standardized tool internet addiction test (IAT) developed by Dr. Kimberly Young. Young's tools consist of 20 items that 
measures mild, moderate and severe level of Internet Addiction. Response was made on 6-point scale and the response categories were assigned weights from 0 to 5 .

\section{Procedure of data collection}

After the selection of the tool, the researcher contacts the mentioned college. In order to assess the internet addiction of the PG final year students pursuing their PG course, standardizes test was administered on sample of 48 students. The researcher prepared a Google form to collect the data. To collect data, the researcher personally contacts all the postgraduate final year students studying in Govt. College, Sundargarh and taking prior permission from the coordinator. After that researcher share the created Google link to the students Whats-app groups. The investigator expressed her purpose of the study and described the procedure to fill-up or responding various items of the tool. The collected response sheets were scored by using different statistical techniques.

\section{Statistical techniques used}

For the present study the investigator used mean, $\mathrm{SD}$, correlation, percentage and t-test for analysis the collected data.

\section{Analysis and Interpretation}

In order to fulfil the objectives of present study, analysis and interpretation of data is presented as follows:

\section{Objective 1}

Table 1 and Fig. 1 indicates the level of internet addiction. It was found that $52 \%$ students are comes under in mild level of internet addiction, $40 \%$ that is 19 students out of 48 students are comes under in moderate and $8.33 \%$ that is only 4 students out of 48 students are comes under in sever internet addiction level.

Table 1: Level of internet addiction

\begin{tabular}{lll}
\hline Level & $\mathbf{N}$ & $\mathbf{\%}$ \\
\hline Mild & 25 & $52 \%$ \\
Moderate & 19 & $40 \%$ \\
Severe & 4 & $8.33 \%$ \\
\hline Total & $\mathbf{4 8}$ & $\mathbf{1 0 0 \%}$ \\
\hline
\end{tabular}

(Mild 20-49, moderate 50-79 E severe 80-100)

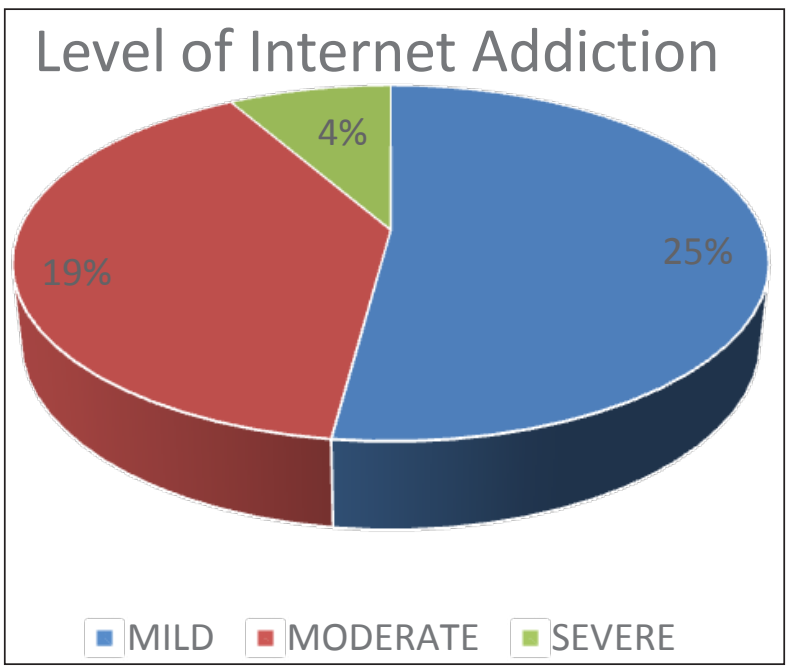

Fig. 1: Level of Internet Addiction

\section{Objective 2}

To study the impact of internet addiction on academic achievement of postgraduate final year students, an average score of internet addiction was calculated and two separate groups are formed such as above average internet addicted postgraduate final year students and below average internet addicted postgraduate final year students. The variation in academic achievement of both groups was obtained by using t-test.

Table 2: Impact of Internet Addiction on Academic Achievement of Postgraduate final year students

\begin{tabular}{|c|c|c|c|c|c|c|c|}
\hline Variable & $\begin{array}{l}\text { Achieve } \\
\text { average } \\
\text { student }\end{array}$ & $\begin{array}{l}\text { of above } \\
\text { net addicted pg } \\
\text { 3) }\end{array}$ & $\begin{array}{l}\text { Achieve } \\
\text { average } \\
\text { pg stud }\end{array}$ & $\begin{array}{l}\text { of below } \\
\text { net addicted } \\
J=25 \text { ) }\end{array}$ & df & t-value & Significant level \\
\hline \multirow{2}{*}{$\begin{array}{l}\text { Internet } \\
\text { Addiction }\end{array}$} & MEAN & SD & MEAN & SD & \multirow{2}{*}{46} & \multirow{2}{*}{0.53424} & \multirow{2}{*}{$\begin{array}{l}\text { Not significant at } \\
\text { both } 0.05 \text { and } 0.01 \\
\text { levels }\end{array}$} \\
\hline & 7.453 & 0.9828 & 7.644 & 1.117 & & & \\
\hline
\end{tabular}

At $0.05=2.02$ and at $0.01=2.69$. 
The table 2 indicates that impact of internet addiction on academic achievement of postgraduate final year students. The $\mathrm{t}$-value came out to be 0.53424 which is less than the table value at both 0.05 and 0.01 levels of significance with the df 46 . Thus, it can be interpreted that there is no considerable difference in the academic achievement of both groups. So, the null hypothesis i.e., there exists negative impact of internet addiction on academic achievement of postgraduate final year student accepted.

\section{Objective 3}

To study the significant gender variation in the internet addiction and academic achievement of the postgraduate final year students, mean score, standard deviation and t-ratio computed.

The table 3 shows that mean difference between male and female postgraduate final year students on internet addiction. The critical ratio came out to be 0.47192 , which is less than the table value at both 0.05 level and 0.01 level of significance with the $\mathrm{df} 47$. Thus, it can be interpreted that there is no considerable gender variation in internet addiction. So, the null hypothesis i.e., there exists no significant difference between internet addiction of postgraduate final year students in relation to their gender is accepted.

\section{Objective 4}

To examine the correlation between internet addiction and academic achievement of postgraduate final year students, researcher used Pearson product moment coefficient of correlation method.

The table 4 indicates that correlation between internet addition and academic achievement of the
Post Graduate students. The correlation between internet addiction and academic achievement of postgraduate final year students is $(r=-0.07514)$, which is weak negative correlation. Thus, it can be interpreted that there is weakest negative correlation between internet addiction and academic achievement of the postgraduate final year students. So, the null hypothesis i.e., there is no relationship between internet addiction and academic achievement of postgraduate final year students is rejected.

\section{Major Findings}

On the basis of analysis and interpretation of data, the main findings were discovered in relation to each objective and present below:

$\square$ It was found that $52 \%$ students are comes under in mild level of internet addiction, $40 \%$ that is 19 students out of 48 students are comes under in moderate and $8.33 \%$ that is only 4 students out of 48 students are comes under in sever internet addiction level.

$\square$ It is found that internet addiction has negative impact on academic achievement of above average internet addicted and below average internet addicted postgraduate final year students.

$\square$ There is weakest negative correlation between academic achievement and internet addiction of postgraduate final year students studying in govt college, Sundargarh.

$\square$ There is exists no significant difference between male and female students among internet addiction on academic achievement.

Table 3: Gender wise variation in the internet addiction

\begin{tabular}{|c|c|c|c|c|c|c|c|}
\hline Variable & Male ( & & Femal & & Df & T-Ratio & Remark \\
\hline \multirow{2}{*}{ Internet Addiction } & Mean & SD & Mean & SD & \multirow{2}{*}{-47} & \multirow{2}{*}{0.471922009} & \multirow{2}{*}{$\begin{array}{l}\text { Not } \\
\text { significan }\end{array}$} \\
\hline & 50.875 & 17.86984952 & 47 & 19.12203373 & & & \\
\hline
\end{tabular}

At $0.05=2.02$ and at $0.01=2.69$.

Table 4: correlation between internet addiction and academic achievement

\begin{tabular}{llll}
\hline Variables & $\mathbf{N}$ & $\mathbf{r}^{\prime}$ & Remark \\
\hline Internet addiction & 48 & -0.07514 & Negative correlation \\
Academic achievement & 48 & & \\
\hline
\end{tabular}




\section{Discussion and implications of results}

The main objective of this study was to study the impact of academic achievement on academic achievement of postgraduate final year students. First of all, scores of internet addiction were calculated individually than calculated an average score of 48 students than two separate groups are formed such as achievement of above average internet addicted Postgraduate final year students and achievement of below average internet addicted postgraduate final year students. The variation in academic achievement of both groups was obtained by using t-test. T-value 0.534 which suggested that internet addiction has negative impact of academic achievement of postgraduate final year students. On the basis of some existing literature, it was hypothesized that internet addiction would have negative impact on academic achievement of the students. The result is in accordance with the stated hypothesis. Students' academic performance greatly depends on the student's health, study habits, how hard works and time management for every academic works. Young (1998) suggested that the internet can distract students from their study. Other several studies also reported that internet has negative impact on students' academic success and their mental health (Shaigan and Khushgeet, 2014 \& Yunyun and Ping, 2018). All these previous studies support the current findings that academic achievement is the most important predictor of internet addiction.

Some study reported that no gender difference in internet addiction and academic achievement among male and female students (Akhter, 2013; Azizollah and Enam, 2016 \& Orhan and Nadir, 2017). This study also revealed that no gender difference in internet addiction and academic performance among male and female post graduate students. The findings strengthen the previous research in the gender difference in internet addiction and academic performance of students.

One of other objectives of the present study that was to examine the correlation between internet addiction and academic achievement of postgraduate final year students, researcher used Pearson product moment coefficient of correlation method. Researcher found that $r=-0.07514$, which is weak negative correlation and suggested that internet addiction and academic achievement have no positive correlation. However, current study has some limitations. Firstly, the sample was selected from only one institution and only $2^{\text {nd }}$ year postgraduate students. Secondly quantitative method was used and studied only academic achievement field. Some recommendations are suggested to overcome this limitation like for instance use both quantitative and qualitative method for this study. And also suggested to do more research in the similar and related topic in the future as it is an important issue in the society. Findings of this study indicates that students who have high internet addicted their academic performance can be poor. So, those students should be avoided to using more internet.

\section{CONCLUSION}

The study concludes that internet addition is not the only influence in students' academic achievement many other reasons also effects on students' achievement. Excessive use of Internet during covid-19 pandemic is not a serious problem but looking into the influence of internet addiction on students' academic achievement. This should be aware to prevent the growing of internet addiction.

\section{REFERENCES}

Aggarwal, Y.P. 2013. Statistical methods: concepts, application and computing. New Delhi Sterling Publishers Pvt. Ltd. Noida, U.P, India.

Akhter, N. 2013. Relationship between Internet Addiction and Academic Performance among University Undergraduates. Educational Research and Reviews, 8(19): 1793-1796.

Arbabisarjou, A., Gorgich, E.A.C., Barfroshan, S. and Ghoreishinia, G. 2016. The Association of Internet Addiction with Academic Achievement, Emotional Intelligence and Strategies to Prevention of them from student's Perspectives. International Journal of Humanities and Cultural Studies (IJHCS) ISSN. 2356-5926.

Deepika, K. 2014. Internet addiction and Academic Achievement among $11^{\text {th }}$ grade students in Chennai. Tamil Nadu, India. Conflux Journal of Education, 2(2).

Eldeleklioglu, J. and Meryem, V. 2013. Predictive effects of Academic Achievement, Internet use duration, Loneliness and Shyness on Internet Addiction. Hacettepe Universitesi Egitim Fakultesi Dergisi, 28(28-1): 141-152.

Hamza, S.B., Abdalla, Y.A., Mustafa, A.A.M., Muhmmed, K.A.B. and Husain, N.E.O.S. 2021. The Effects of Internet Addiction on Academic Performance of Medical students at Omdurman Islamic University: An online crosssectional study. DOI: https://doi.org/10.21203/rs-154768/v1. 
Iyitoglu, O. and Celikoz, N. 2017. A Study on Exploring the Impact of Internet Addiction on Academic Achievement. European Journal of Education Studies, 3(5).

Javaeed, A., Jeelani, R., Gulab, S. and Ghauri, S.K. 2020. Relationship between Internet Addiction and Academic Performance of Undergraduate Medical students of Azad Kashmir. Pakistan Journal of Medical Sciences, 36(2): 229.

Khan, M.A., Alvi, A.A., Shabbir, F. and Rajput, T.A. 2016. Effect of Internet Addiction on Academic Performance of Medical students. Journal of Islamic International Medical College, 11(2): 48-51.

Lin, M. 2020. Prevalence of Internet Addiction During the Covid-19 Outbreak and its Risk factors among junior high school students in Taiwan. International Journal of Environmental Research and Public Health, 17(22): 8547.
Mangal, S.K. and Mangal, U. 2020. Research Methodology in Behavioural Science. Delhi PHI Learning Private Limited, Rimjhim House, 111.

Singh, N. and Barmola, K.C. 2015. Internet Addiction, Mental Health and Academic Performance of School Students/ Adolescent. Int. J. Indian Psychol., 2: 98-108.

Yeap, J.A.L., Ramayah, T., Halim, H.A., Ahmad, N.H. and Kurnia, S. 2016. Exploring the Impact of Internet Addiction on Academic Engagement: A Preliminary study on Undergraduates. Indian Journal of Management Science, 6(1): 1 . 
